\title{
Nova ocorrência de Nicolea venustula (Montagu) (Polychaeta, Terebellidae) na costa sul do Brasil $^{1}$
}

\author{
Arno Blankensteyn ${ }^{2}$ \\ Tatiane Regina Moreno ${ }^{2}$
}

\begin{abstract}
Nicolea venustula (Montagu) (Polychaeta, Terebellidae) A new record to the Southern Brazilian coast. Nicolea venustula (Montagu, 1818) is a new record to the southern brazilian coast. A description, ilustrations and a taxonomic discussion is given.

KEY WORDS. Polychaeta, Terebellidae, Nicolea venustula, new record
\end{abstract}

Os invertebrados bentônicos marinhos da costa brasileira são parcialmente conhecidos (LANA et. al. 1996). Para a região sudeste, proporcionalmente à concentração de instituições e especialistas, existe também uma lista maior de bibliografia sobre sistemática e ecologia desta fauna. Os Annelida Polychaeta formam um grupo de elevada representatividade nas diversas associações biológicas em praticamente todos os hábitats marinhos disponíveis (AMARAL \& NONATO 1996). O número de espécies de Polychaeta, por família, citado para a costa do estado de São Paulo pode ser encontrado em recente levantamento feito por AMARAL \& MORGADO (1997).

Os Terebellidae da costa brasileira também foram alvo de levantamentos, embora as principais listas de espécies ainda se encontrem na forma de teses não publicadas. Os Terebellidade são poliquetas que tradicionalmente estão incluídos no grupo dos sedentários. Estes vermes possuem prostômio muito modificado com ausência de aparelhos sensoriais, mas presença de um grande número de tentáculos orais. Os terebelídeos habitam galerias tanto em substratos inconsolidados como sobre superfícies duras, e possuem hábitos alimentares de coleta seletiva de partículas orgânicas depositadas sobre o fundo marinho (FAUCHALD \& JUMARS 1979; HolTHE 1986). Nicolea venustula (Montagu, 1818) constrói seus tubos com uma camada de areia selecionada e fragmentos calcáreos colados em uma matriz pergaminácea.

O objetivo do presente estudo é ampliar a distribuição geográfica de $N$. venustula para a costa sul do Brasil (Paranaguá, Paraná) e apresentar informações sistemáticas e ecológicas dessa espécie.

1) Contribuição número 1157 do Departamento de Zoologia, Universidade Federal do Paraná.

2) Departamento de Zoologia, Universidade Federal do Paraná. Caixa Postal 19020, 81531-990 Curitiba, Paraná, Brasil. 


\section{Nicolea venustula (Montagu, 1818)}

Fig. 1

Terebella venustula Montagu, 1818.

Terebella parva Leuckart, 1849.

Terebella vestita Claparède, 1870.

Nicolea venustula; Fauvel, 1909.

Material examinado. A presente descrição baseia-se em exemplares adultos coletados na Ilha do Mel, Paranaguá, Paraná (253'8 "S; 48¹9'14"W). Tamanho: Comprimento total variando de 5 a $31 \mathrm{~mm}$; largura do tórax 0,5 a $1 \mathrm{~mm}$, com número máximo de 51 segmentos. Corpo claviforme e sem pigmentação no material vivo. Dois pares de brânquias dicotômicas sobre os segmentos II e III, sendo que o primeiro par é maior (Fig. 1a,b). Lamelas laterais ausentes nos segmentos anteriores (Fig. 1a,b). Cerdas notopodiais a partir do segmento IV; 17-18 setígeros torácicos com cerdas capilares limbadas lisas (Fig. 1c); cerdas ventrais a partir do segmento V, em fileiras, com "uncini" alternados a partir do segmento X (Fig. 1d). Escudos glandulares ventrais em 14 segmentos torácicos (Fig. 1a). Papilas nefridiais junto às bases dos notopódios dos segmentos III, VI e VII, sendo estas tubulares nos indivíduos machos adultos. Segmentos abdominais progressivamente reduzidos, com pínulas neuropodiais. Pigídio sem apêndices sensoriais.

Distribuição geográfica. Ártico, Atlântico Norte e Mediterrâneo, Mar Vermelho, África do Sul, costa africana oriental, Oceania e costa sul do Brasil (Paraná, Paranaguá).

Discussão. Nossa identificação concorda com a descrição de HESSLE (1917) e DAY (1967) para a variedade $N$. venustula venustula, a qual apresenta pínulas dos neuropódios abdominais com papila superior. Já $N$. venustula africana, apresenta as pínulas do abdome com apêndices dorsais cirriformes. HoLTHE (1986) descreveu as fileiras duplas dos "uncini" ocorrendo a partir do segmento XI. HESSLE (1917) sinonimizou $N$. venustula com $N$. zostericola (Orsted, 1844). Este procedimento não foi adotado por HoLTHE (1986), embora tenha admitido as dificuldades de separação entre as duas espécies. O gênero Nicolea Fauvel, 1909 foi citado com dúvidas para a costa do Uruguai por RULLIER \& AMOUREUX (1979), sendo coletado por dragagens e arrastos, entre 63 e 270 metros de profundidade, em fundos lodosos e com conchas. Nicolea venustula tem sido registrada sempre em associação com outros organismos de fundos rochosos, com tubos geralmente fixos a algas, ascídias, hidróides e briozoários. Teve seu primeiro registro na costa sul do Brasil, no ano de 1995, ao ser coletada em altas densidades, juntamente com a ascídia colonial Eudistoma carolinense (Van Name, 1945), na Praia de Itapema do Norte, Santa Catarina ( $\left.26^{\circ} 04^{\prime} \mathrm{S} ; 4^{\circ} 36^{\prime} \mathrm{W}\right)$. Nicolea venustula também foi registrada associada à ascídia, em coletas sazonais, no ano de 1996. Através de mergulho autônomo, exemplares de $N$. venustula foram coletados em altas densidades junto a macroalgas na Ilha do Mel e da Figueira ( $25^{\circ} 21^{\prime} 04^{\prime \prime S}$; $48^{\circ} 01^{\prime}$ W), Paraná. A forte relação entre $N$. venustula e substratos biológicos pode explicar o fato desta não ter sido registrada anteriormente, por meio de métodos convencionais da bentologia, como dragagens e pegadores de fundo, os quais são utilizados com dificuldades em ambientes 
sublitorais transicionais (entre substratos rochosos e fundos inconsolidados). O material coletado encontra-se no Departamento de Zoologia, Universidade Federal do Paraná.

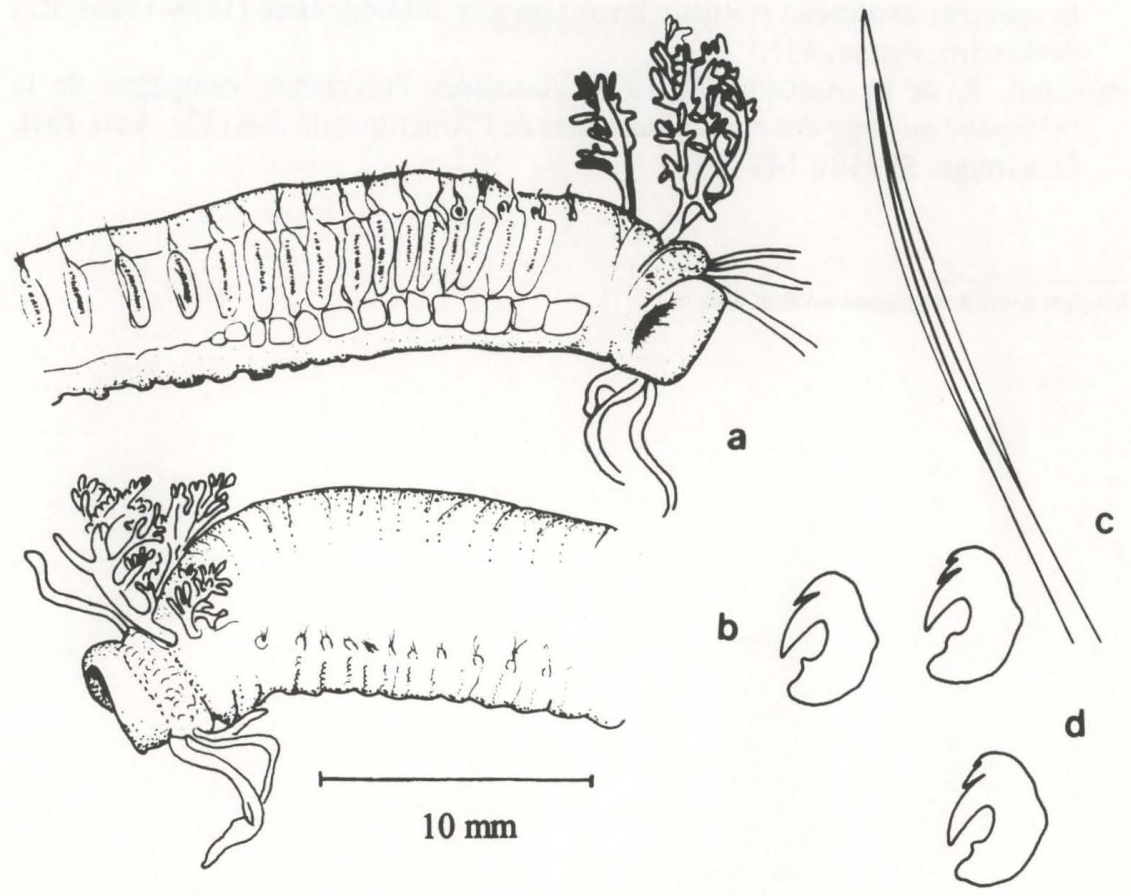

Fig. 1. Nicolea venustula. (a) Vista latero-ventral da região anterior do corpo; (b) vista latero-dorsal da região anterior do corpo; (c) cerda capilar limbada; (d) vista lateral dos "uncini" torácicos.

\section{REFERÊNCIAS BIBLIOGRÁFICAS}

Amaral, A.C.Z. \& E.H. Morgado. 1997. Polychaeta, p.163-175. In: A.E. Migotto \& C.G. Tiago. Biodiversidade do Estado de São Paulo, Brasil. 3. invertebrados marinhos. São Paulo, Fapesp, 310p.

Amaral, A.C.Z. \& E.F. NonATO. 1996. Annelida Polychaeta: características, glossário e chaves para famílias e gêneros da costa brasileira. Campinas, Editora da Unicamp, 124p.

DAY, J.H. 1967. A monograph on the Polychaeta of Southern Africa. British Mus. Nat. Hist. Publ. 656: XXXVIII+878p.

FAUCHALD, K. \& P.A. JUMARS. 1979. The diet of worms: a study of polychaete feeding guilds. Oceanogr. Mar. Biol. Ann. Rev. 17: 193-284.

Hessle, C. 1917. Zur kenntnis der terebellomorphen Polychaeten. Zool. Bidr. Upps. 5: 39-258.

Holthe, T. 1986. Evolution, systematics and distribution of the Polychaeta 
Terebellomorpha, with a catalogue of the taxa and a bibliography. Gunneria 55: 1-236.

LANA, P.C.; M.G. CAMARGO; R.A. BROGIM \& V.J. ISAAC. 1996. O bentos da costa brasileira: avaliação crítica e levantamento bibliográfico (1858-1996). Rio de Janeiro, Femar, 431p.

Rullier, F. \& L. Amoureux. 1979. Annelides Polychetes: campagne de la "Calipso" au large des côtes atlantiques de l'Amerique du Sud (33). Ann. Inst. Oceanogr. 55 (10): 145-206.

Recebido em 17.X.1998; aceito em 28.VI.1999. 